\title{
Noise-Free Estimation of Temporal Change in Seismic Wave Attenuation Using High-Stable Vibration Sources.
}

Shuhei Tsuji ( $\nabla$ shuhei.tsuji@gmail.com )

Nagoya Daigaku Daigakuin Kankyogaku Kenkyuka

Koshun Yamaoka

Nagoya University Graduate School of Environmental Studies: Nagoya Daigaku Daigakuin Kankyogaku Kenkyuka

Ryoya Ikuta

Faculty of Science, Shizuoka University

Full paper

Keywords: attenuation, amplitude, coseismic change, water injection, artificial seismic source, ACROSS

Posted Date: September 9th, 2020

DOl: https://doi.org/10.21203/rs.3.rs-70160/v1

License: (c) (i) This work is licensed under a Creative Commons Attribution 4.0 International License. Read Full License 


\section{Title page:}

2 Title: Noise-free estimation of temporal change in seismic wave attenuation using

3 high-stable vibration sources.

4 Author \#1: (Corresponding Author) Shuhei Tsuji, Graduate School of Environmental

5 Studies, Nagoya University, Furo-cho, Chikusa-ku, Nagoya 464-8601, Japan,

6 stsuji@seis.nagoya-u.ac.jp

7 Author \#2: Koshun Yamaoka, Earthquake and Volcano Research Center, Graduate

8 School of Environmental Studies, Nagoya University, Furo-cho, Chikusa-ku, Nagoya

9 464-8601, Japan, kyamaoka@seis.nagoya-u.ac.jp

10 Author \#3: Ryoya Ikuta, Faculty of Science, Shizuoka University, 836 Oya, Suruga,

11 Shizuoka 422-8529, Japan, ikuta.ryoya@shizuoka.ac.jp

12 (go to new page)

13 


\section{Abstract}

We developed a method to detect changes in attenuation in transfer functions

16 obtained by precisely controlled artificial seismic sources, namely Accurately

17 Controlled Routinely Operated Signal System (ACROSS), and applied it to monitor the

18 temporal changes for in-situ data collected by previous studies. Our method, together

19 with the usage of the ACROSS sources, is less susceptible to change in noise level to

20 which conventional methods such as envelope calculation suffer. The method utilizes

21 the noise level that is independently estimated in the frequency domain. Thus, we can

22 eliminate the influence of the noise by subtracting it from the observed signal. To test

23 the performance, we applied this method to a dataset obtained at Awaji Island, Japan

24 from 2000 to 2001 . We detected the changes in amplitude with several causes including

ground motion in an earthquake and water injection experiment. At the 2000 Western

26 Tottori earthquake $\left(\mathrm{Mw}_{\mathrm{w}}=6.6\right.$, Epicenter distance of $\left.165 \mathrm{~km}\right)$, a sudden decrease in

27 amplitude up to 5\% followed by gradual recovery are clearly observed. These coseismic

28 changes in amplitude are consistent with the opening of fluid-filled cracks as proposed

29 by previous studies. We convert the amplitude change into $\Delta Q^{-1}$, which gives similar 
30 values as reported by previous studies using natural earthquakes. Increases in amplitude

31 up to $5 \%$ associated with water injection experiments are also observed. During these

32 experiments, the amplitude increased several days after the beginning of the injection

33 and recovered to the previous level. This may be the result of a stress increase caused by

34 the injection followed by a saturation increase by water diffusion.

\section{Keywords}

37 attenuation; amplitude; coseismic change; water injection; artificial seismic source;

38 ACROSS

39

40 Main Text

$41 \quad$ Introduction

Temporal changes in the propagation property of seismic waves have

43 been studied using both seismic velocity and attenuation. In previous studies

44 coseismic changes, among others, draw the attention of researchers because

45 they display clear synchronization to earthquakes and their relation to 
relevant phenomena can be discussed quantitatively.

48 changes in seismic velocity. Various methods have been used to detect delays

49 in seismic velocity during earthquakes in many locations. Seismic

50 interferometry (e.g. Brenguier et al. 2008; Hobiger et al. 2016; Ikeda and Tsuji

51 2018), which does not need artificial sources, is generally used to measure the

52 temporal variation of seismic velocity in recent years. In contrast,

53 experiments with artificial seismic sources (e.g. Ikuta et al. 2002; Tsuji et al.

54 2018; Wang et al. 2020) are also carried out to identify coseismic velocity

55 changes with better resolution. In most cases the seismic velocity delays

56 during the earthquakes and recovers gradually over time. These phenomena

57 are accounted for with a fracturing of subsurface rock (Sawazaki et al. 2009;

58 Nakata and Snieder 2011) and/or crack opening by stress (Grêt et al. 2006;

59 Silver et al. 2007) or pore pressure changes (Ikuta and Yamaoka 2004;

60 Sawazaki and Snieder 2013) caused by the strong ground motions of

61 earthquakes. 
63 Temporal changes in the spectral ratio of natural earthquakes are often used

64 to estimate the change of attenuation (Chun et al. 2004; Titzschkau et al.

65 2010; Kelly et al. 2013). As the source amplitudes are difficult to estimate

66 precisely, spectral ratio is used assuming that the $\mathrm{Q}$ is independent of

67 frequency. Coda-Q has often been used to estimate the temporal variation of

68 attenuation in the region surrounding earthquake faults (Chouet 1979;

69 Huang and Kisslinger 1992; Sugaya et al. 2009) or in volcanic regions (Fehler

70 et al. 1988; Tonatiuh Domínguez et al. 2003). As the coda-Q reflects both

71 scattering and intrinsic attenuation, they also pay attention to the spectral

72 ratio in discussing intrinsic attenuation. In contrast to these studies,

73 Yamamura et al. (2003) revealed the periodic variation of attenuation

74 associated with earth tides using a piezo-electric actuator as a seismic source,

75 which produces seismic signals of constant amplitude. Despite the use of high

76 resolution seismic sources, no remarkable earthquakes occurred in their

77 experiment period and they did not detect a coseismic change of attenuation. 
79 temporal change of amplitude of seismic signals observed by high stability

80 artificial sources. Here we show the result of the application of one of our

81 methods to the data set which includes the effects of strong earthquake

82 motions. We used the Accurately Controlled Routinely Operated Signal

83 System (ACROSS) as a high stability artificial source which makes it possible

84 to obtain accurate and stable transfer functions with adequate estimation of

85 noise level. ACROSS was developed for precise monitoring of propagation

86 property by means of continuous seismic waves excited by a precisely

87 controlled rotating eccentric weight (Kumazawa and Takei 1994), which

88 enables us to obtain transfer functions between sources and receivers

89 continuously and with precision (Kumazawa et al. 2007). With these

90 characteristics, ACROSS is able to monitor very small changes in the medium

91 in various fields, such as Sakurajima volcano, Japan (Yamaoka et al. 2014;

92 Maeda et al. 2015) or the Nankai trough subduction zone (Tsuji et al. 2018). 
94 the Awaji site, western Japan (Ikuta et al. 2002; Ikuta and Yamaoka 2004),

95 where a surface fault appeared at the 1995 Hyogo-ken Nanbu Earthquake

96 (Kobe earthquake, $\mathrm{M}_{\mathrm{jma}}$ 7.3) (Nakata and Yomogida 1995). At this site, an

97 experiment with two ACROSS vibrators was carried out from January 2000

98 to April 2001. They monitored change in travel time for P and S waves and

99 found coseismic changes in two earthquakes which caused relatively large

100 ground motion at the site (Ikuta et al. 2002; Ikuta and Yamaoka 2004). These

101 two earthquakes, the 2000 Western Tottori earthquake (WT) and the 2001

102 Geiyo earthquake (GY), had magnitudes and epicenter distances of $\mathrm{M}_{\mathrm{W}}$ 6.6,

$103165 \mathrm{~km}$ and $\mathrm{M}_{\mathrm{W}} 6.4,215 \mathrm{~km}$, respectively. Ikuta and Yamaoka (2004) proposed

104 a possible mechanism for these observations from the anisotropic changes of

105 transfer function and the strain change observed at a bore-hole strain meter

106 in the site. They interpret that the changes in the travel time were caused by

107 self-opening of the preferred oriented, fluid-filled cracks due to pore pressure

108 increase. Their interpretation indicates that changes in seismic attenuation

109 can be caused by friction loss of fluid in the cracks by the earthquake motion. 
110 This is the direct motivation for this study.

111

\section{Experiments at Awaji site}

\section{ACROSS experiments}

114 First, we review the experiment that were carried out at Awaji site.

115 Two ACROSS vibrators and two deep borehole seismometers were deployed

116 at this site to monitor the temporal changes in the propagation property of

117 the seismic wave (Yamaoka et al. 2001; Ikuta et al. 2002). The ACROSS

118 vibrators were operated continuously for 15 months in the period from

119 January 4, 2000, through April 9, 2001. The two ACROSS vibrators generated

120 elastic waves with frequency modulation in different frequency ranges

121 covering between 10 to $23 \mathrm{~Hz}$. As the modulation period is $5 \mathrm{~s}$, the sources

122 produce discrete signals with an interval of $0.2 \mathrm{~Hz}$ in the frequency domain.

123 Unlike recent experiments with ACROSS sources, no rotation switching had

124 been implemented at that time, i.e. the weight rotates only clockwise viewing

125 from the top throughout the experiment period. Seismic waves excited by the

126 ACROSS vibrators are observed at the bottoms of two boreholes in the 
experiment site. The seismometers in the boreholes are three-component

128 velocity-type sensors with a natural frequency of $3 \mathrm{~Hz}$ and $2 \mathrm{~Hz}$ for vertical

129 and horizontal components in the $800 \mathrm{~m}$ deep borehole, and $4.5 \mathrm{~Hz}$ for the

$1301700 \mathrm{~m}$ deep borehole. Both sensors are located almost vertically downward

131 from the sources with small horizontal distances of $50 \mathrm{~m}$ and $120 \mathrm{~m}$ from the

132 vibrators, respectively (Figure 1).

133 Water injection experiments

134 In this site, water injection experiments were conducted repeatedly

135 from 1997 to monitor a healing process in the Nojima Fault zone after the

1361995 Kobe earthquake (Ando 2001). Water was pumped into the $1700 \mathrm{~m}$

137 borehole to inject the water into the bedrock. The effects of injection are

138 monitored by a pressure gauge in the $800 \mathrm{~m}$ borehole, a strain meter at the

139 bottom of the borehole, and seismic stations around the site. An optical fiber

140 thermometer is deployed in the $1700 \mathrm{~m}$ borehole to measure the temperature

141 distribution in the well. During the injection, no appreciable change is

142 observed below a depth of $580 \mathrm{~m}$, and Yamano and Goto (2001) conclude that

143 the water leaked out from a joint near the $540 \mathrm{~m}$ mark. A contraction of 
144 approximately $10^{-8}-10^{-7}$ was observed by the strain meter at the $800 \mathrm{~m}$

145 borehole (Mukai and Fujimori 2007). A cluster of earthquakes migrated with

146 the speeds of $20-80 \mathrm{~m} / \mathrm{h}$, which are interpreted as induced earthquakes

147 (Tadokoro et al. 2000). Hydraulic conductivity estimated by strain records

148 reduced by 50\% from 2000 to 2003 (Mukai and Fujimori 2007), which are

149 interpreted as a healing of the fractures after the Kobe earthquake.

150 One of the water injection experiments was carried out in the

151 experiment period of ACROSS monitoring at this site. Four injection

152 operations were conducted. The $1^{\text {st }}$ operation was performed on January 4,

1532000 , but was aborted due to the leaking of the water at the well top. The

$1542^{\text {nd }}, 3^{\text {rd }}$, and $4^{\text {th }}$ operations were performed in January 22-26, January $31-$

155 February 5, and March 3-11, respectively, and were completed successfully.

156 The water was injected at constant pressures of 2.9, 4.0, and 4.5 MPa

157 respectively during each of the three operations. A total of $457 \mathrm{~kL}$ of water

158 was injected during the four operations (Nishigami 2001). Transfer

159 functions during the water injections were obtained only for the $800 \mathrm{~m}$ 
160 borehole. The transfer function for the $1700 \mathrm{~m}$ borehole was hidden by the

161 noise of the injection into the borehole. The analysis of the transfer function

162 shows that the $\mathrm{S}$ wave travel time started to change after the beginning of

163 the $2^{\text {nd }}$ and the $4^{\text {th }}$ operations and recovered before the end of each injection

164 period (Yamaoka and Ikuta 2001).

165

166 Method

167

We estimated a temporal change in attenuation using a series of

168 transfer functions that are obtained in Ikuta et al. (2002). In this study, we

169 performed an independent data screening to remove the observation period

170 in which ACROSS vibrators are not in proper operation. The first step of the

171 data screening was conducted based on operation logs of the ACROSS source.

172 Rotation frequency and mass position are logged in 1-s intervals and can be

173 used to evaluate the quality of the operation. Cross covariance of the transfer

174 functions for each 1 -h interval with the reference time is also used for data

175 screening in the second step. We removed the data for which the cross 
177 the seismic observation systems. carried out with a weighted average adopting the inverse maximum

181 amplitude in each segment as the weight. The stacked waveforms were

182 deconvolved with the source function of the force of the ACROSS vibrators

183 in the frequency domain to obtain transfer functions. As we used $100 \mathrm{~s}$ long

184 data for stacking, its Fourier transform contains spectral components with

185 an interval of $0.01 \mathrm{~Hz}$. As the period of frequency modulation was $5 \mathrm{~s}$, the

186 source signal gives spectral components with an interval of $0.2 \mathrm{~Hz}$. This

187 causes an ACROSS source signal to appear every 20 components in the

188 frequency series for each vibration source. We refer to the components of the

189 ACROSS signal as signal channels. With the exception of the signal channels,

190 the components consist of noise referred to as the noise channel. We assumed

191 that the signal channels also contain noise whose variance is equivalent to 
192 the mean of the variance of the two noise channels next to it. We selected $\mathrm{P}$ and $\mathrm{S}$ waves in the transfer function in the time

194 domain, which is calculated by inverse Fourier transformation of the signal 195 channel. $\mathrm{P}$ and $\mathrm{S}$ waves were selected for the $800 \mathrm{~m}$ and $1700 \mathrm{~m}$ boreholes 196 in the same way as Ikuta et al. (2002) and Ikuta and Yamaoka (2004) for 197 comparison. The waveform including either $\mathrm{P}$ or $\mathrm{S}$ waves were selected with 198 a $20 \%$ Hanning window of 0.3 s centered at the travel time of $\mathrm{P}$ or $\mathrm{S}$ waves 199 estimated from the typical velocity of the country rock. P waves were 200 selected from the vertical components and $\mathrm{S}$ waves were selected from the 201 horizontal components (Figure 2). The transfer functions in the time domain 202 shown in Figure 2 was obtained by inverse Fourier transformation of those 203 in the frequency domain. P, S, and several later phases were identified in the 204 transfer functions for the seismometers in both the $800 \mathrm{~m}$ and the $1700 \mathrm{~m}$ 205 boreholes. We estimated a temporal change in amplitudes of $\mathrm{P}$ and $\mathrm{S}$ waves 207 by calculating the ratio of the total energy of the ACROSS signal in 
208 selected time windows of the 1 -h transfer functions to those of the

209 reference transfer function. We selected the transfer function from 14:00 to

$210 \quad$ 15:00 of January 19, 2000 as the reference transfer function as used in

211 Ikuta et al. (2002). The ratio $r$ can be calculated as the following equation

$$
r_{l}^{2}=\frac{\sum_{k}\left(G_{k l} G_{k l}^{*}-\sigma_{k l}^{2}\right)}{\sum_{k} G_{k 0} G_{k 0}^{*}}
$$

213 where $G_{k l}$ denotes the Fourier transform of the transfer function extracted

214 by the windows in the time domain. $\sigma_{k l}^{2}$ denotes noise variance in the time

215 window. $G_{k 0}$ is the Fourier transform of the reference transfer function under

216 the same time window for $G_{k l}$. The subscripts $k$ and $l$ denote the frequency

217 component and calendar time, respectively. The method can avoid the

218 apparent change of signal amplitude caused by the changes of noise

219 amplitude, which conventional methods such as envelope calculation suffer.

220 This method takes the advantage of ACROSS in that noise level can be

221 estimated accurately.

223 for the selected windows including $\mathrm{P}$ and $\mathrm{S}$ waves are estimated based on 
224 the method in Ikuta et al. (2002). The transfer functions $G_{k}$ extracted with 225 the Hanning window onto the time domain data is calculated as equation (4) 226 in Ikuta et al. (2002) as follows:

$$
G_{k}=\sum_{j=0}^{N} \frac{X_{j}}{S_{j}} H_{k-j}
$$
where $X_{j}$ and $S_{j}$ is the $\mathrm{j}$-th spectral component of the stacked 229 waveform and the source function, respectively. $H_{k-j}$ is the $(k-j)$-th 230 component of the Fourier transform of the Hanning window. $N$ is the 231 number of data in the frequency domain. Similarly, we can calculate noise 232 variance corresponding to each component of the transfer functions. The 233 noise variance extracted by the window function can be calculated as follows:

$$
\sigma_{k}^{2}=\sum_{j=0}^{N} \frac{\varepsilon_{j}^{2}}{S_{j}^{2}} H_{k-j}^{2}
$$

235 where $\varepsilon_{j}^{2}$ is noise variance at $\mathrm{j}$-th frequency component. We applied this method to the same data that are obtained by 237 Ikuta et al. (2002) at the Awaji site. However, we analyzed the signal of each 238 component of the seismometers instead of synthetizing the radial and 
transverse component. Thus, we name two horizontal components as H1

240 and $\mathrm{H} 2$ for both sensors in the $800 \mathrm{~m}$ and $1700 \mathrm{~m}$ boreholes. $\mathrm{H} 1$ and $\mathrm{H} 2$

241 components in the $800 \mathrm{~m}$ borehole are directed $\mathrm{N} 126^{\circ} \mathrm{E}$ and $\mathrm{N} 216^{\circ} \mathrm{E}$ and

242 those of the $1700 \mathrm{~m}$ borehole are directed $\mathrm{N} 90^{\circ} \mathrm{E}$ and $\mathrm{N} 180^{\circ} \mathrm{E}$. The $\mathrm{S}$ phase

243 that appears in each component is denoted S-H1 and S-H2.

\section{Results}

$247 \mathrm{H} 1$, and S-H2 observed by the sensors in the $800 \mathrm{~m}$ and $1700 \mathrm{~m}$ boreholes are

248 shown in Figure 3. The variations of the amplitudes are calculated using the

249 method explained above for each component. We plot hourly data to show the

250 daily variations as well as long-term or event related variations. The travel

251 time variation is also calculated after Ikuta et al. (2002) for comparison. In

252 this plot, we calculated them for each component and showed hourly variation

253 instead of the plots as in Ikuta et al. (2002), which showed radial and

254 transverse components with a moving average over $24 \mathrm{~h}$. 


\section{Change in travel time}

258 Ikuta et al. (2002). Estimated travel time is shown in the top three panels in

259 Figure 3. General trends in variation for the 800 and $1700 \mathrm{~m}$ boreholes are

260 quite similar. Long term variation for $\mathrm{P}$ and $\mathrm{S}$ waves such as gradual delay

261 from January to March in 2000, gradual recovery from April to May, and

262 gradual advance from July to September are observed. Sudden delay at

263 extremely heavy rain on September 11 is visible in all the components. The

264 delay is preceded by a two-month-long advance of travel time, which

265 corresponds to the dry summer season at this site. Coseismic delay and

266 gradual recovery are observed at the teleseismic event on October 6 . In

267 addition, changes which may be associated with the $2^{\text {nd }}$ and $4^{\text {th }}$ water

268 injection experiments are clearly observed for the $800 \mathrm{~m}$ borehole, although

269 there is no mention of this event in Ikuta et al. (2002). 


\section{Change in amplitude}

272

Several characteristics in the amplitude variation are seen

273 throughout the experimental period (See the bottom three panels in Figure

274 3). The amplitude of the $\mathrm{P}$ wave for both the $800 \mathrm{~m}$ and $1700 \mathrm{~m}$ boreholes

275 gradually decreased from January to February, shortly following the onset of

276 the ACROSS experiment. The overall pattern of the amplitude variation of $\mathrm{P}$

277 waves is similar for both the $800 \mathrm{~m}$ and the $1700 \mathrm{~m}$ boreholes, although

278 variation is larger in the $1700 \mathrm{~m}$ than that in the $800 \mathrm{~m}$ borehole. This may

279 indicate that the region causing the attenuation change spreads below the

280 sensor of the $800 \mathrm{~m}$ borehole as well as above it. Relatively large amplitude

281 increases are observed for S-H2 of the $1700 \mathrm{~m}$ sensor from February to April.

suddenly for the S-H1 for both the $800 \mathrm{~m}$ and the $1700 \mathrm{~m}$ boreholes after a

gradual change from the mid-August. They changed in the opposite direction.

285 The amplitude decreases for the $800 \mathrm{~m}$ borehole after a gradual increase but

286 increases for the $1700 \mathrm{~m}$ borehole after a gradual decrease. On the other hand,

287 few changes can be seen in P and S-H2. In contrast to the amplitude change, 
288 the travel time is delayed for both $\mathrm{P}$ and $\mathrm{S}$ waves. This change is interpreted 289 as the delay of the source motion with reference to the weight rotation caused 290 by energy dissipation immediately local to the source. It is difficult to 291 interpret the cause of the amplitude variation in terms of the source-ground 292 interaction only. It may be caused by the interference of multi-path waves 293 that suffer radiation variation near the source.

294 Diurnal variations that correlated well with the changes in 295 temperature (Figure 4), were also observed. For the $800 \mathrm{~m}$ borehole, the 296 amplitude has positive correlation with temperature for all the phases. The 297 P and S-H1 often show larger variation than that of the S-H2. The maximum 298 variation in the $\mathrm{P}$ and $\mathrm{S}-\mathrm{H} 1$ reach approximately $5 \%$ and that of the $\mathrm{S}-\mathrm{H} 2$ 299 approximately $3 \%$. For the $1700 \mathrm{~m}$ borehole, daily variation of $\mathrm{P}$ and $\mathrm{S}-\mathrm{H} 1$ are 300 opposite to that of $\mathrm{S}-\mathrm{H} 2 . \mathrm{P}$ and $\mathrm{S}-\mathrm{H} 1$ have positive correlation with the 301 temperature whereas $\mathrm{S}-\mathrm{H} 2$ has negative correlation. The daily variation of $\mathrm{P}$ 302 (approximately 10\%) is larger than that of S-H1 and S-H2 (approximately $3 \%$ ). 
304 phases for the $1700 \mathrm{~m}$ boreholes is seen. We checked total energy of the

305 transfer function in the frequency domain and found a step-like decrease in

306 energy at 08:00 on October 31 . The ratio of this decrease is almost the same

307 for all the components. The level of ground noise of all the components of the

308 sensor were analyzed because we suspected that this change was caused by

309 a problem in the observation system, such as a change in amplification gain.

310 However, no significant difference in noise level was found except for a small

311 step-like increase of noise level in the UD component. The spectrum of the

312 noise also did not change at that time. This means that data-logging

313 instruments did not cause the signal decrease. The change might be caused

314 by a change in the coupling of the sensors against the well casing.

315

316 Coseismic Change

317 We analyzed the seismic changes caused by the Western Tottori

318 earthquake (WT) in 2000 and the Geiyo earthquake (GY) in 2001, as their

319 effect on the travel time is intensively discussed in Ikuta and Yamaoka (2004). 
323 than the GY earthquake, which follows the same tendency as travel times.

324 For the WT earthquake, a sudden drop of approximately $3 \%$ and $5 \%$ are

325 observed in S-H2 for the $800 \mathrm{~m}$ borehole and $\mathrm{S}-\mathrm{H} 1$ for the $1700 \mathrm{~m}$ borehole.

326 Gradual recoveries lasted approximately one week after the earthquakes

327 are observed in $\mathrm{P}$ and $\mathrm{S}$ for both boreholes (Figure 4a). The amplitude

328 recovered to almost the same level as before the earthquake. However, for

329 the GY earthquake, only S-H2 of the $800 \mathrm{~m}$ borehole shows a clear step-like

330 decrease of $1 \%$ (Figure $4 \mathrm{~b}$ ). Gradual recovery is not observed in any phases

331 of any sensors.

\section{Change at water injections}

Water injection causes a change in the transfer function both in

336 observed in P and S-H1 of the $800 \mathrm{~m}$ borehole in the $2^{\text {nd }}$ and $4^{\text {th }}$ period of

337 water injection. The magnitude of the change is up to approximately $3 \%$ for 
338 both phases of the $2^{\text {nd }}$ period and approximately $5 \%$ for both phases of the

$3394^{\text {th }}$ period. Travel times of S-H1 and S-H2 also show advances in the $2^{\text {nd }}$ and

$3404^{\text {th }}$ periods of the injection experiment although neither Ikuta et al. (2002)

341 nor Ikuta and Yamaoka (2004) noted these findings in their studies. The

342 timing of the advances in the travel times are almost the same as those of

343 the increase in amplitude. The period to the recovery is almost the same for

344 S-H2 of travel time and P and S-H1 of amplitude. No significant change in

345 amplitude and travel time is observed in the $3^{\text {rd }}$ period.

\section{Discussions}

348 Interpretation of the change in amplitude

349 Fluid migration in cracks or pores is usually considered as a cause of

350 attenuation. The effects of fluid saturation in attenuation have been widely

351 studied with laboratory experiments. For example, Winkler et al. (1979)

352 measured attenuation for dry, partially saturated, and fully saturated

353 Massilon sandstone under several confining pressures. They demonstrated

354 that the attenuation generally increases with saturation increase, and 
decreases with an increase of confining pressure. The effect of confining

356 pressure is noticeable in saturated rocks. Pressure increase causes closure of

357 cracks or pores and thus, reduces the attenuation.

359 explained by a combination of saturation and pressure increase. The

360 amplitude observed in the $2^{\text {nd }}$ and the $4^{\text {th }}$ periods of the injection experiments

361 increased for several days following the beginning of the injection and then

362 returned to original levels. This observation may reflect a pressure increase

363 from the water injection from the well reducing attenuation along the ray

364 path, but diffusion of the injected water increased the fluid saturation in the

365 ray path region, increasing attenuation. However, if this mechanism operated

366 identically also in the $3^{\text {rd }}$ period the amplitude should be increased. This

367 suggests the existence of other compromising factors. mechanism proposed by Ikuta and Yamaoka (2004), where they explained

370 the delay of travel time during earthquakes with the opening of fluid-filled 
cracks due to an increase in pore pressure caused by strong vibrations.

372 When new fluid-filled cracks are generated in the rock, viscous loss by the

373 fluid causes energy dissipation and increases attenuation.

\section{Comparison in terms of change in attenuation}

comparison with coseismic changes observed in other studies. We assume the

amplitude ratio $\gamma$ can be written as,

$$
\gamma(f)=\frac{\frac{1}{d} A_{0} \exp \left(-\frac{2 \pi f d}{2 c} Q^{-1}\right)}{\frac{1}{d} A_{0} \exp \left(-\frac{2 \pi f d}{2 c} Q^{*-1}\right)}=\exp \left(-\frac{\pi f d}{c} \Delta Q^{-1}\right)
$$

where, $d$ is the distance of sensors from the source, $A_{0}$ is the amplitude at

the source, $\omega$ is the angular frequency of an elastic wave, $\mathrm{c}$ is the velocity of

383 after the earthquake. We put $\Delta Q^{-1}=Q^{-1}-Q^{*-1}$.

$$
\text { We may assume that the amplitude ratio we obtained in this study }
$$




$$
\Delta Q^{-1}=-\frac{c}{\pi \bar{f} d} \ln (\alpha)
$$

388 Herein, we assumed no velocity change in the equation because the coseismic

389 velocity change is sufficiently small (<0.5\%). With this method, the amplitude

390 changes associated with the WT and GY earthquakes were converted into

$391 \Delta Q^{-1}$ and compared with the changes in $\mathrm{Q}^{-1}$ that had been obtained in

392 various regions by other methods. Table 1 shows the amplitude ratio of the

393 transfer function before and after the earthquake obtained by the amplitude

394 changes at the WT and GY earthquakes.

395

396 Table 1: Coseismic steps of amplitudes

\begin{tabular}{|l|l|l|l|l|}
\hline \multicolumn{2}{|l|}{ Step at WT } & \multicolumn{2}{l|}{ Step at GY } \\
\hline & $0800 \mathrm{~m}$ & $1700 \mathrm{~m}$ & $0800 \mathrm{~m}$ & $1700 \mathrm{~m}$ \\
\hline P-UD & 0.95 & 0.94 & -- & -- \\
\hline S-H1 & -- & 0.95 & -- & -- \\
\hline S-H2 & 0.97 & 0.97 & 0.99 & -- \\
\hline
\end{tabular}

397 Ratio of the amplitude of the transfer functions before and after the

398 earthquakes in each sensor and each phase obtained by the comparison of

399 the estimated change in amplitude. This corresponds to a in equation (4)."-

400 -" indicates that no significant change was observed. 
403 shown in Table 1 and $V_{P}=4.0[\mathrm{~km} / \mathrm{s}], V_{S}=2.5[\mathrm{~km} / \mathrm{s}]$. In this calculation

404 we put $f=16[\mathrm{~Hz}]$ which corresponds to the center of the source frequency 405 of the ACROSS operation. The results are shown in Table 2, in which $\Delta Q^{-1}$ 406 are estimated in range of $1.0 \times 10^{-3}$ to $1.0 \times 10^{-2}$.

408 Table 2: $\Delta \boldsymbol{Q}^{-\mathbf{1}}$ obtained with equation (3)

\begin{tabular}{|l|l|l|l|l|}
\hline \multirow{2}{*}{} & \multicolumn{2}{|l|}{ Step at WT } & \multicolumn{2}{l|}{ Step at GY } \\
\cline { 2 - 5 } & $0800 \mathrm{~m}$ & $1700 \mathrm{~m}$ & $0800 \mathrm{~m}$ & $1700 \mathrm{~m}$ \\
\hline P-UD & 0.01 & 0.003 & -- & -- \\
\hline S-H1 & -- & 0.002 & -- & -- \\
\hline S-H2 & 0.002 & 0.001 & 0.001 & -- \\
\hline
\end{tabular}

$409 \Delta Q^{-1}$ estimated with equation (5) under the assumption of $V_{S}=4.0[\mathrm{~km} / \mathrm{s}]$,

$\left.410 V_{P}=2.5[\mathrm{~km} / \mathrm{s}]\right)$ and $f=16 \mathrm{~Hz}$.

413 previous studies with spectral ratio methods. For example, Kelly et al. (2013)

414 reported that $\Delta Q^{-1}$ in the fault region of the 2004 Parkfield earthquake $\left(\mathrm{M}_{\mathrm{W}}\right.$ 
416 associated with the $1999 \mathrm{Chi}-\mathrm{Chi}$ earthquake $\left(\mathrm{M}_{\mathrm{W}}\right.$ 7.6). The $\mathrm{Qs}_{\mathrm{s}}$ was changed

417 from 238 to 157 , which corresponds to $2.2 \times 10^{-3}$ of $\Delta Q^{-1}$.

\section{Conclusions}

421 artificial seismic source, ACROSS, and applied it to in-situ data. The

422 amplitude change was obtained by calculating the energy ratio of the

423 transfer function of each period to that of a reference time. The energy of the

424 noise is estimated to avoid apparent change in amplitude caused by noise

425 level drift. We applied this method to the data acquired at the Awaji site by

426 Ikuta et al. (2002). Various changes including the effects of water injection

427 and strong ground motion by earthquakes are detected. An amplitude

428 increase of $10 \%$ is observed associated with the water injection experiment.

429 The changes in the water injection experiments can be explained by the

430 changes in the degree of saturation of cracks in rocks. A coseismic decrease 
431 of amplitude was observed for the 2000 Western Tottori earthquake and the

4322001 Geiyo earthquake with a maximum decrease of approximately $10 \%$. The

433 coseismic changes can be explained by the mechanism proposed by Ikuta and

434 Yamaoka (2004).

435

436

437 Declarations

438

\section{Availability of data and materials}

439

Please contact Dr. Ikuta Ryoya for the transfer functions and operation

440

logs which we used for this analysis.

441

Precipitation and temperature data at Gunka station are retrieved from the

442

JMA website

443

(http://www.data.jma.go.jp/gmd/risk/obsdl/index.php , In

444

Japanese)

445

\section{Competing interests}

446

The authors declare that they have no competing interests. 


\section{Funding}

This study was founded by Nagoya University.

\section{Authors' contributions}

TS developed the method, carried out the analysis, and drafted the manuscript. YK supervised TS and developed the method together. IR provided the data of the experiments at Awaji Site and supported in developing the method. All authors read and approved the final manuscript. by JMA. We would like to thank Editage (www.editage.com) for English language editing.

459

460

\section{$461 \quad$ References}

462 Ando M (2001) Geological and geophysical studies of the Nojima Fault from drilling: 

seismological observations. Science 321:1478-1481 . https://doi.org/10.1126/science.1160943

Chouet B (1979) Temporal variation in the attenuation of earthquake coda near Stone https://doi.org/10.1029/GL006i003p00143

472 Chun K-Y, Henderson GA, Liu J (2004) Temporal changes in P wave attenuation in the Loma Prieta rupture zone . J Geophys Res Solid Earth 109:1-15 . https://doi.org/10.1029/2003jb002498 observed during an eruption of Mount St. Helens. J Geophys Res Solid Earth 93:4367-4373 . https://doi.org/10.1029/JB093iB05p04367

478 Grêt A, Snieder R, Özbay U (2006) Monitoring in situ stress changes in a mining 
environment with coda wave interferometry. Geophys J Int 167:504-508 . https://doi.org/10.1111/j.1365-246X.2006.03097.x

481

482

483

484

485

486

487

488

489

490

491

492

493

494

Hobiger M, Wegler U, Shiomi K, Nakahara H (2016) Coseismic and post-seismic velocity changes detected by passive image interferometry: Comparison of one great and five strong earthquakes in Japan. Geophys J Int 205:1053-1073 . https://doi.org/10.1093/gji/ggw066

Huang ZX, Kisslinger C (1992) Coda-Q before and after the 1986 Andreanof Islands earthquake. Pure Appl Geophys 138:1-16 . https://doi.org/10.1007/BF00876711

Ikeda T, Tsuji T (2018) Temporal change in seismic velocity associated with an offshore MW 5.9 Off-Mie earthquake in the Nankai subduction zone from ambient noise cross-correlation. Prog Earth Planet Sci 5:62 . https://doi.org/10.1186/s40645-018-0211-8

Ikuta R, Yamaoka K (2004) Temporal variation in the shear wave anisotropy detected using the Accurately Controlled Routinely Operated Signal System (ACROSS). J Geophys Res Solid Earth 109:B09305. https://doi.org/10.1029/2003JB002901 
497 Kelly CM, Rietbrock A, Faulkner DR, Nadeau RM (2013) Temporal changes in attenuation associated with the 2004 M6.0 Parkfield earthquake. J Geophys Res Solid Earth 118:630-645 . https://doi.org/10.1002/jgrb.50088 Mura, Naka-gun, Ibaraki-ken, Japan

Kumazawa M, Takei Y (1994) Active method of monitoring underground structures by means of Accurately Controlled ROtary Seismic Source (ACROSS). 1. Purpose and principle. Abstruct Seismol. Soc. Japan p158 Iguchi M (2015) A subsurface structure change associated with the eruptive activity at Sakurajima Volcano, Japan, inferred from an accurately controlled source. Geophys Res Lett 42:5179-5186 . https://doi.org/10.1002/2015GL064351 

the Nojima fault estimated using strain changes due to water injection experiments.

513 Nakata N, Snieder R (2011) Near-surface weakening in Japan after the 2011 Tohoku-

514 Oki earthquake. Geophys Res Lett 38:1-5 . https://doi.org/10.1029/2011GL048800

515 Nakata T, Yomogida K (1995) Surface fault characteristics of the 1995 Hyogoken-

$516 \quad$ Nambu earthquake. J Nat disaster Sci 16:1-9

517 Nishigami K (2001) Summary of the wather injection experiment, shallow structure of

518 the Nojima fault and its healing process. Chikyu Mon 23:232-235

519 Sawazaki K, Sato H, Nakahara H, Nishimura T (2009) Time-lapse changes of seismic

520 velocity in the shallow ground caused by strong ground motion shock of the 2000

521 Western-Tottori earthquake, Japan, as revealed from coda deconvolution analysis.

$522 \quad$ Bull Seismol Soc Am 99:352-366 . https://doi.org/10.1785/0120080058

523 Sawazaki K, Snieder R (2013) Time-lapse changes of P- and S-wave velocities and

524 shear wave splitting in the first year after the 2011 tohoku earthquake, Japan:

$525 \quad$ Shallow subsurface. Geophys J Int 193:238-251.

526 https://doi.org/10.1093/gji/ggs080 
527 Silver PG, Daley TM, Niu F, Majer EL (2007) Active source monitoring of cross-well seismic travel time for stress-induced changes. Bull Seismol Soc Am 97:281-293 . https://doi.org/10.1785/0120060120 of scattering environment in the crust after the 1995 Hyogo-ken Nanbu earthquake, Japan. Bull Seismol Soc Am 99:435-440 . https://doi.org/10.1785/0120080012

533 Tadokoro K, Ando M, Nishigami K (2000) Induced earthquakes accompanying the migration. J Geophys Res Solid Earth 105:6089-6104 . https://doi.org/10.1029/1999JB900416

537 Titzschkau T, Savage M, Hurst T (2010) Changes in attenuation related to eruptions of Mt. Ruapehu Volcano, New Zealand. J Volcanol Geotherm Res 190:168-178 . https://doi.org/10.1016/j.jvolgeores.2009.07.012 
544 Tsuji S, Yamaoka K, Ikuta R, Kunitomo T, Watanabe T, Yoshida Y, Katsumata A

545 (2018) Secular and coseismic changes in S-wave velocity detected using ACROSS

546 in the Tokai region. Earth, Planets Sp 70:146 . https://doi.org/10.1186/s40623-018-

548 Wang B, Yang W, Wang W, Yang J, Li X, Ye B (2020) Diurnal and semidiurnal P and $\mathrm{S}$ - wave velocity changes measured using an airgun source. J Geophys Res Solid Earth 125:e2019JB018218. https://doi.org/10.1029/2019JB018218

551 Wang Y-J, Ma K-F (2015) Investigation of the Temporal Change in Attenuation Within the Ruptured Fault Zone of the 1999 Mw7.3 Chi-Chi, Taiwan Earthquake. Pure Appl Geophys 172:1291-1304 . https://doi.org/10.1007/s00024-014-0854-3

554 Winkler K, Nur A, Gladwin M (1979) Friction and seismic attenuation in rocks. Nature 277:528-531 . https://doi.org/10.1038/277528a0

556 Yamamura K, Sano O, Utada H, Takei Y, Nakao S, Fukao Y (2003) Long-term 
559 Yamano M, Goto S (2001) Long-term temperature monitoring in a borehole drilled into

560 the Nojima Fault, Southwest Japan. Isl Arc 10:326-335 .

$561 \quad$ https://doi.org/10.1111/j.1440-1738.2001.00331.x

562 Yamaoka K, Ikuta R (2001) Observation of variation in seismic velocity assiciated with

563 the water injection experiments using ACROSS. Chikyu Mon 23:285-289

564 Yamaoka K, Kunitomo T, Miyakawa K, Kobayashi K, Kumazawa M (2001) A trial for

565 monitoring temporal variation of seismic velocity using an ACROSS system. Isl

$566 \quad$ Arc 10:336-347. https://doi.org/10.1111/j.1440-1738.2001.00332.x

567 Yamaoka K, Miyamachi H, Watanabe T, Kunitomo T, Michishita T, Ikuta R, Iguchi M

568 (2014) Active monitoring at an active volcano: amplitude-distance dependence of

$569 \quad$ ACROSS at Sakurajima Volcano, Japan. Earth, Planets Sp 66:32 .

$570 \quad$ https://doi.org/10.1186/1880-5981-66-32

571

572

$573 \quad$ Figure Captions

574

- Figure 1 

borehole seismometers. Figures are from Figure 1 in Ikuta et al., 2004. indicates the location of the ACROSS at Awaji site. (b) Location of the ACROSS and borehole seismometers. The solid triangles show the location of $0800 \mathrm{~m}$ and $1700 \mathrm{~m}$-deep boreholes. The onset map shows the details of the location configuration. The circles show seismometers in the borehole. (c) Cross section of the $800 \mathrm{~m}$ and $1700 \mathrm{~m}$-deep boreholes.

585 Reference transfer function in time domain and selected $\mathrm{P}$ and $\mathrm{S}$ phase

586 for $800 \mathrm{~m}$ and $1700 \mathrm{~m}$ sensors. Transfer functions on 14:00 January 19,

5872000 are used for the reference. Area with red background shows selected

$588 \quad \mathrm{P}$ and $\mathrm{S}$ phase for calculating the change in amplitude and travel time.

589 We selected $\mathrm{P}$ waves from UD components (P-UD) and S waves from two

590 horizontal components (S-H1 and S-H2). 
592 Change in travel time and amplitude in all period. The changes in travel

593 time (yellow back) that are calculated after Ikuta et al., (2002) and

594 changes in amplitude (green back) that is obtained by the proposed

595 method. The center row indicates rainfall observed at Gunka station, the

596 nearest meteorological station. Periods with blue shading show the

597 periods of the water injection experiments. Red vertical lines show the

598 timing of the earthquakes mentioned in Ikuta and Yamaoka (2004).

599

- Figure 4

600 Change in amplitudes approximately 10 days before and after the

601 occurrence of the 2000 Western Tottori (WT) earthquake and 2001 Geiyo

602 (GY) earthquake. The magnitudes and epicenter distances for WT and GY

603 are $\mathrm{MW}=6.6,165 \mathrm{~km}$ and $\mathrm{MW}=6.4,215 \mathrm{~km}$, respectively. Bottom row

604 shows temperature at Gunka station.

605

- Figure 5

606 Change in amplitude around the water injection experiments. The bottom 
607 row shows the temperature observed at Gunka station. Blue background

608 indicates the periods of the injection experiments. In the period of the

609 water injection experiment, the transfer function of the $1700 \mathrm{~m}$ sensor

610 could not be analyzed because of the noise of the injection. 
(a)

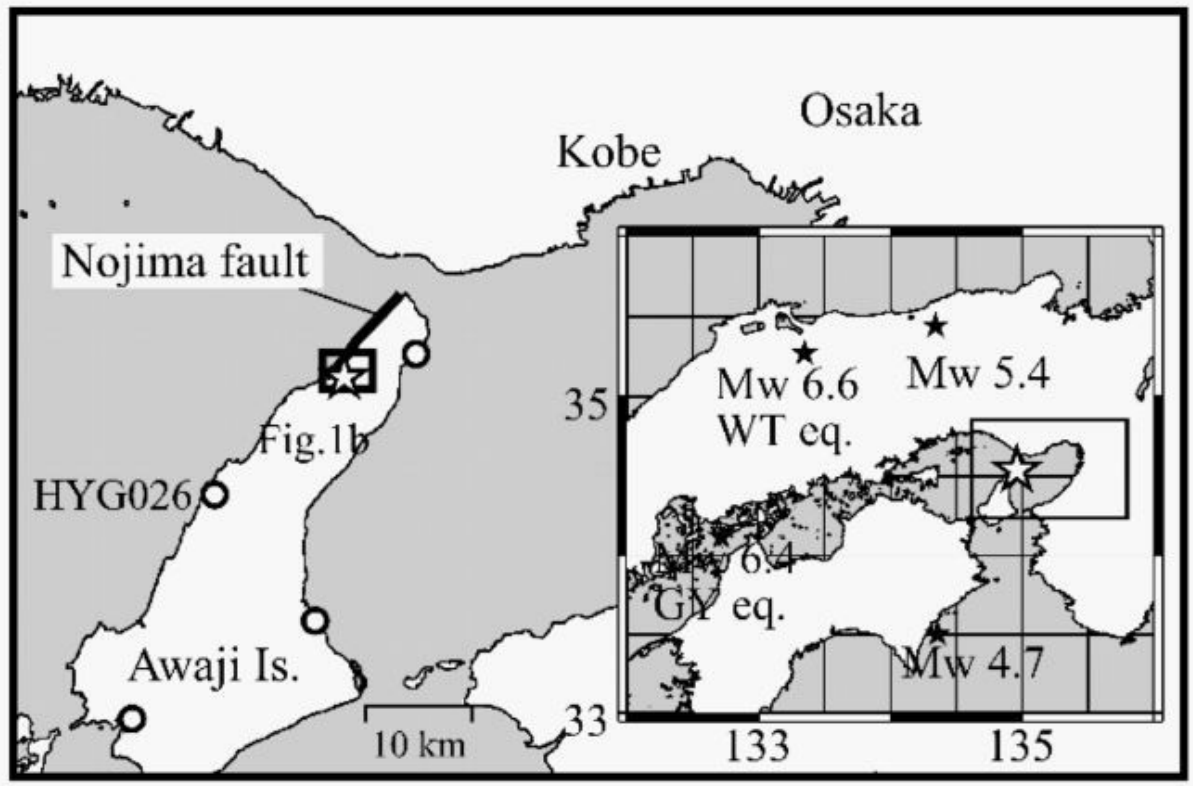

(b)

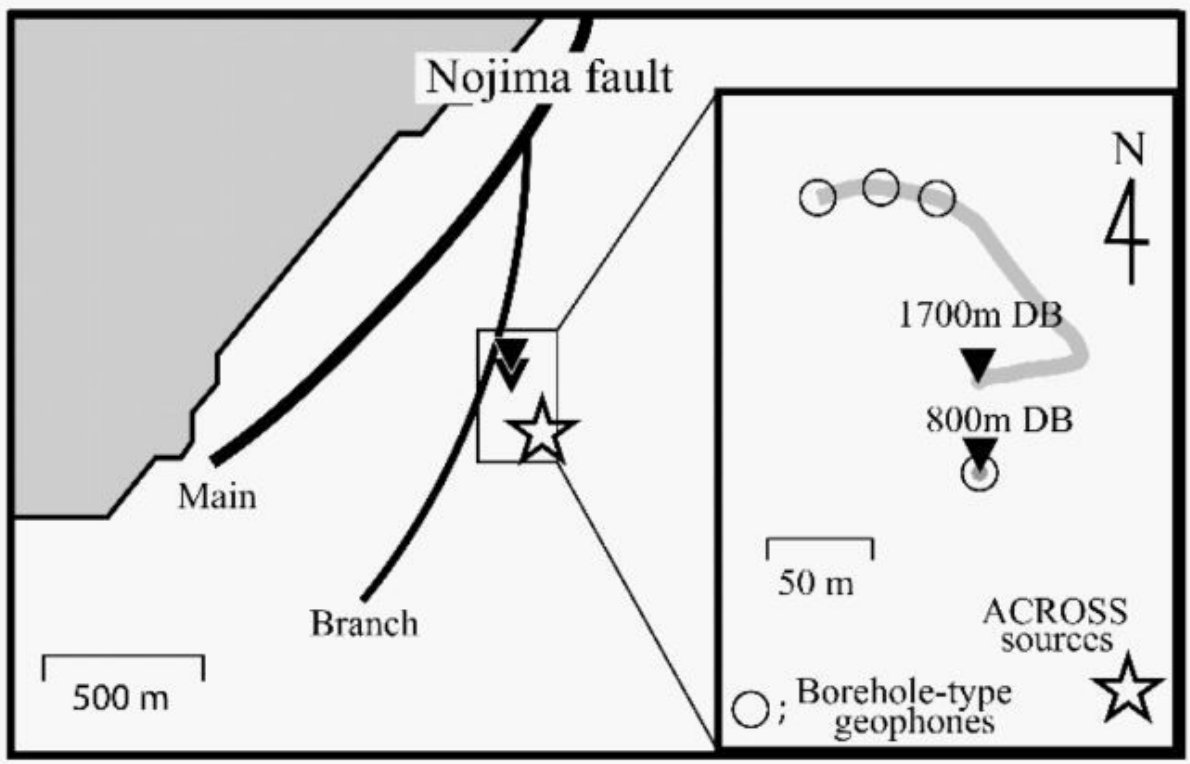

(c)

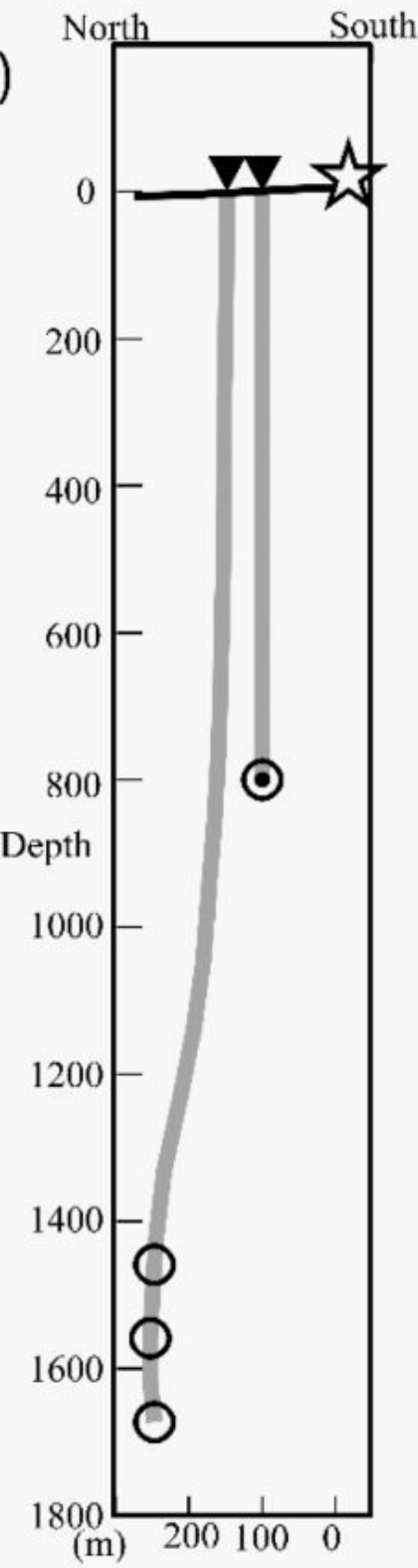

Figure 1

Location of Awaji site, epicenter of earthquakes, ACROSS vibrator, and borehole seismometers. Figures are from Figure 1 in Ikuta et al., 2004. (a) Location of the ACROSS site and epicenter of four earthquakes with strong ground motion during the ACROSS experiment. The open star indicates the location of the ACROSS at Awaji site. (b) Location of the ACROSS and borehole seismometers. The solid triangles show the location of $0800 \mathrm{~m}$ and $1700 \mathrm{~m}$-deep boreholes. The onset map shows the details of the location configuration. The circles show seismometers in the borehole. (c) Cross section of the $800 \mathrm{~m}$ and 1700 m-deep boreholes. 

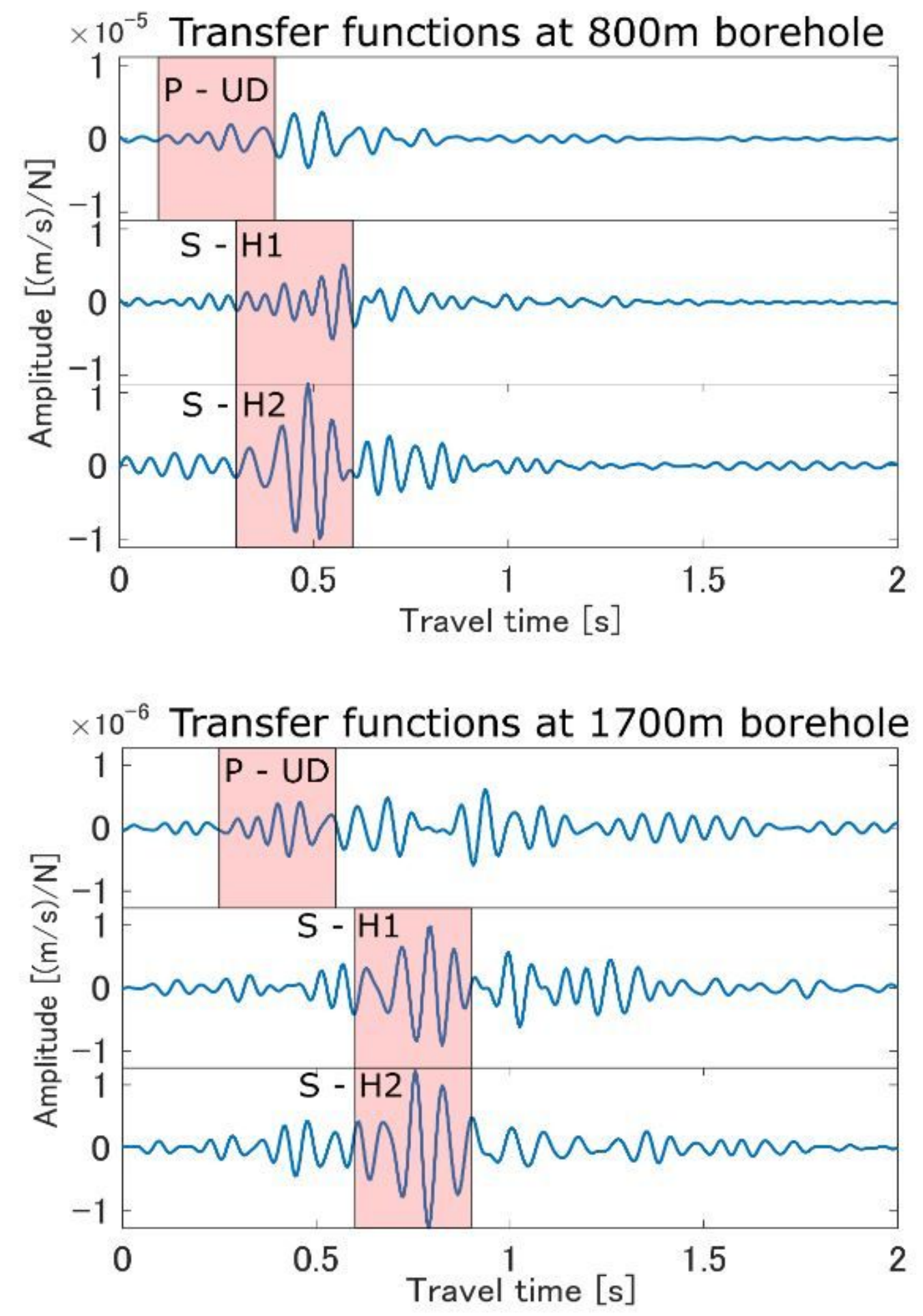

Figure 2

Reference transfer function in time domain and selected $\mathrm{P}$ and $\mathrm{S}$ phase for $800 \mathrm{~m}$ and $1700 \mathrm{~m}$ sensors. Transfer functions on 14:00 January 19, 2000 are used for the reference. Area with red background shows selected $\mathrm{P}$ and $\mathrm{S}$ phase for calculating the change in amplitude and travel time. We selected $\mathrm{P}$ waves from UD components (P-UD) and S waves from two horizontal components (S-H1 and S-H2). 


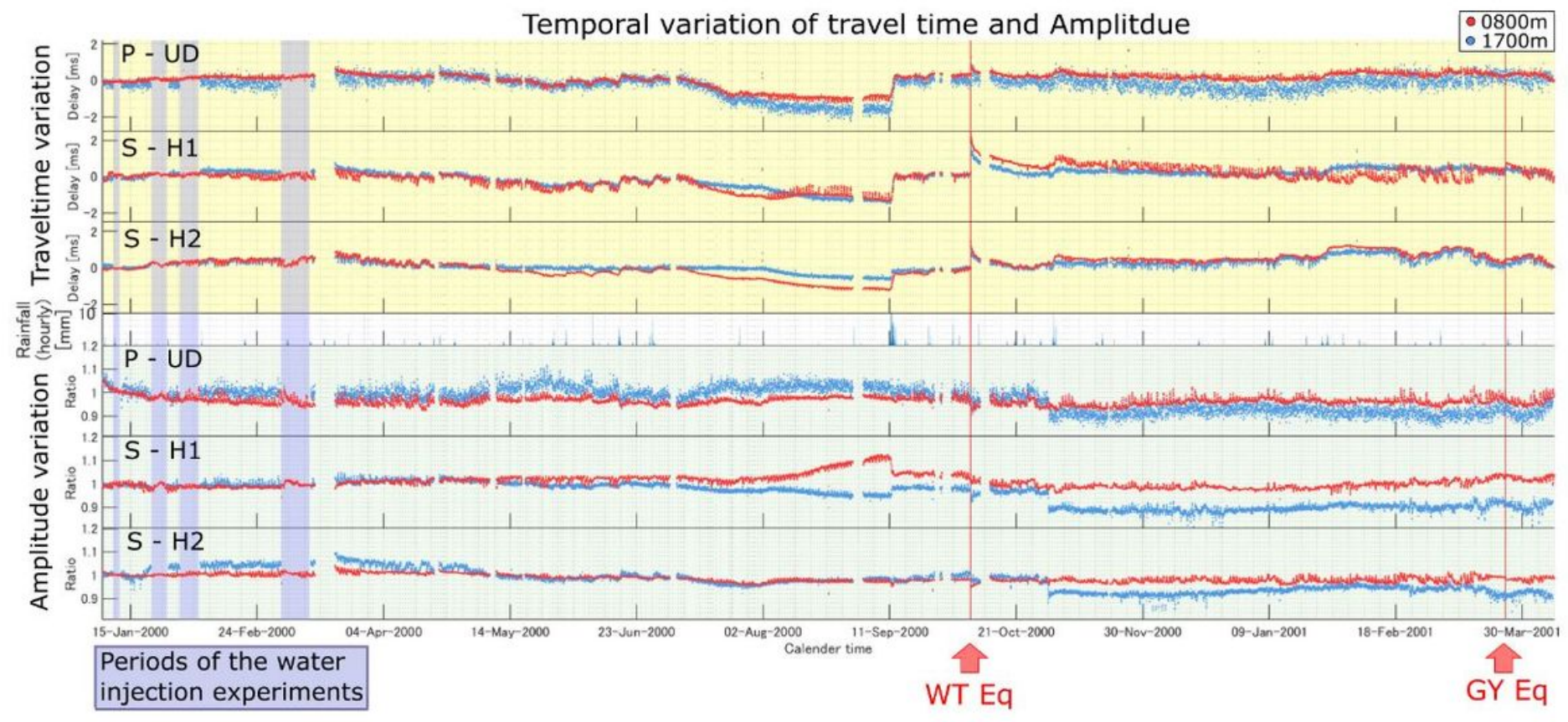

\section{Figure 3}

Change in travel time and amplitude in all period. The changes in travel time (yellow back) that are calculated after lkuta et al., (2002) and changes in amplitude (green back) that is obtained by the proposed method. The center row indicates rainfall observed at Gunka station, the nearest meteorological station. Periods with blue shading show the periods of the water injection experiments. Red vertical lines show the timing of the earthquakes mentioned in Ikuta and Yamaoka (2004). 

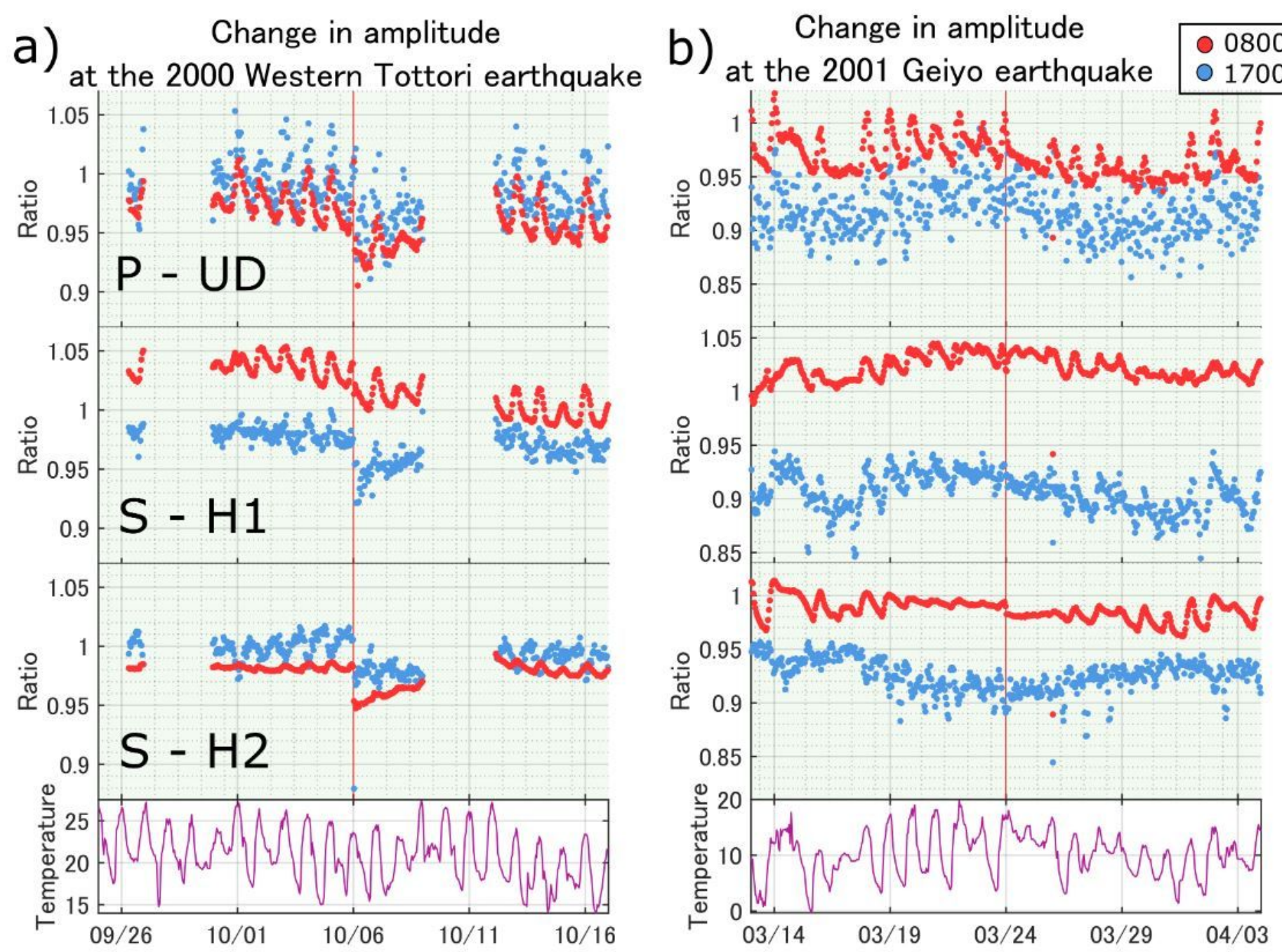

\section{Figure 4}

Change in amplitudes approximately 10 days before and after the occurrence of the 2000 Western Tottori (WT) earthquake and 2001 Geiyo (GY) earthquake. The magnitudes and epicenter distances for WT and $\mathrm{GY}$ are $\mathrm{MW}=6.6,165 \mathrm{~km}$ and $\mathrm{MW}=6.4,215 \mathrm{~km}$, respectively. Bottom row shows temperature at Gunka station. 


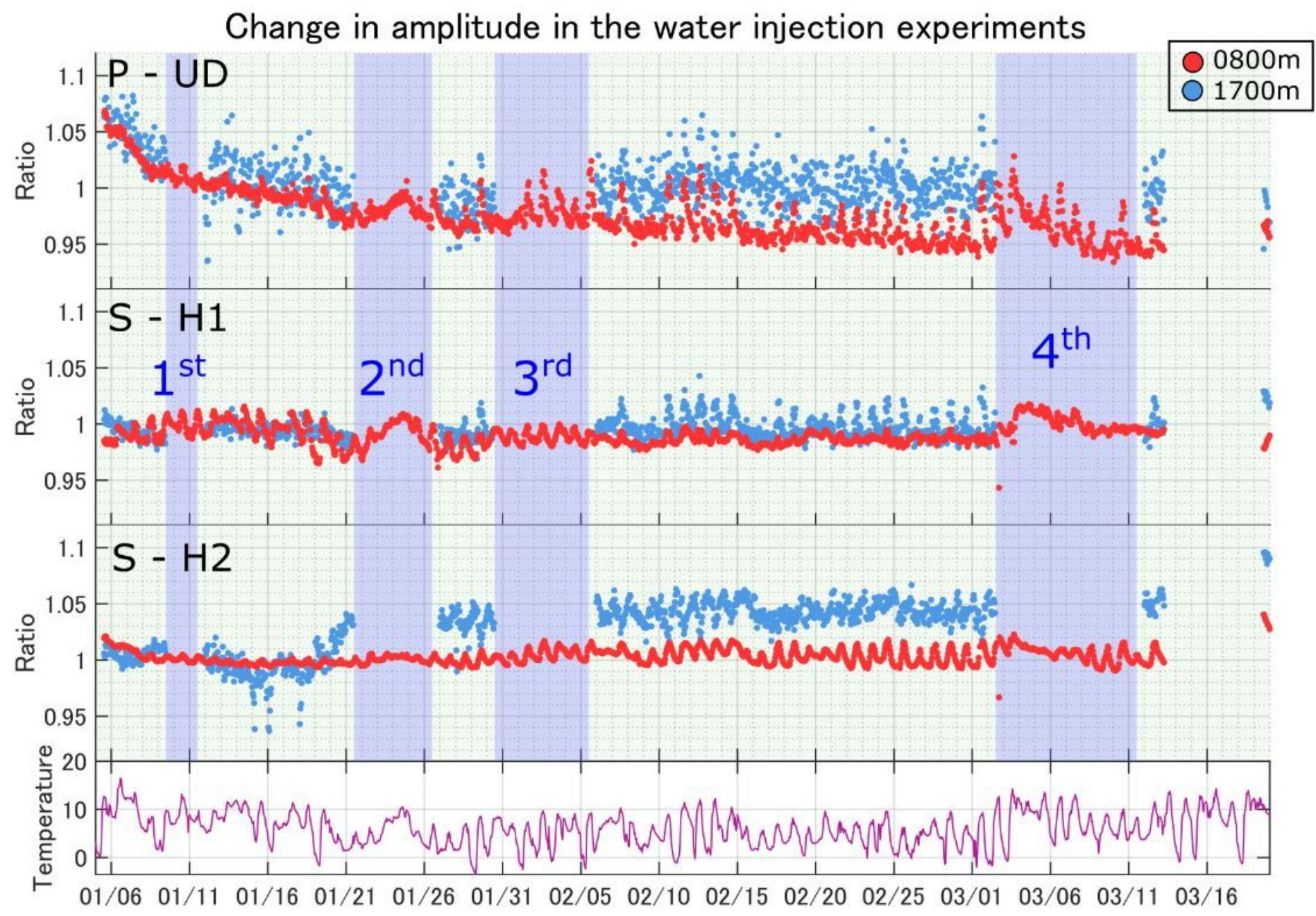

Figure 5

Change in amplitude around the water injection experiments. The bottom row shows the temperature observed at Gunka station. Blue background indicates the periods of the injection experiments. In the period of the water injection experiment, the transfer function of the $1700 \mathrm{~m}$ sensor could not be analyzed because of the noise of the injection.

\section{Supplementary Files}

This is a list of supplementary files associated with this preprint. Click to download.

- GraphicsAbstract.png 